\title{
O INTÉRPRETE COMUNITÁRIO: SUA AGÊNCIA NA ENTREVISTA DE SOLICITAÇÃO DE REFÚGIO
}

\section{COMMUNITY INTERPRETERS: THEIR AGENCY AT AN ASYLUM SEEKING INTERVIEW}

Fernanda de Deus Garcia* Sabine Gorovitz ${ }^{* *}$

\footnotetext{
* Professora Substituta no Departamento de Línguas Estrangeiras e Tradução na Universidade de Brasília. Mestre em Estudos da Tradução na Universidade de Brasília (2019).

E-mail: fernanda.deusgarcia@gmail.com

** Professora Associada no Departamento de Línguas Estrangeiras e Tradução da Universidade de Brasília. E-mail: sabinegz@gmail.com
} 
Resumo: 0 texto aborda o papel do intérprete comunitário na interação entre o oficial de elegibilidade e o solicitante de refúgio no contexto das entrevistas de solicitação de refúgio no Comitê Nacional para Refugiados (Conare), órgão do Ministério da Justiça brasileiro, responsável pelo deferimento ou não da solicitação de refúgio pelo migrante. Partindo de uma abordagem sociolinguística interacional, buscou-se analisar como o intérprete se faz presente na interação durante a entrevista, e de que forma se manifesta linguisticamente. Para conduzir esse estudo, foi realizada uma pesquisa de campo empírica com observação participante em algumas entrevistas no Conare, além do acesso a diversas gravações dessas interações para a condução das análises. Estas revelam estratégias de mediação não apenas linguística, mas também social e cultural por parte do intérprete.

Palavras-chave: Intérprete comunitário; Mediação linguística e cultural; Sociolinguística interacional; Migração e refúgio.

Abstract: This paper addresses the role of the community interpreter in the interaction between the eligibility officer and the asylum seeker during the interviews to seek asylum at the Brazilian National Committee for Refugees (Conare), a department of the Brazilian Ministry of Justice, responsible for approving or rejecting asylum requests by the migrant. Based on the interactional sociolinguistics approach, we aim at analyzing how the interpreter's presence is noted, and how it is linguistically manifested. To give grounds to such study, an empirical field research, with participant observation, was conducted at some Conare interviews, in addition to analyses of some recordings of the interactions, to which we were given access. The analyses show strategies of the interpreters' mediation, not only of a linguistic nature, but also of a social and cultural nature.

Keywords: Community interpreter; Linguistic and cultural mediation; Interactional sociolinguistics; Migration and asylum. 


\section{Introdução}

Busca-se aqui refletir sobre o papel do intérprete comunitário e como sua presença configura a interação entre o oficial de elegibilidade (agente público encarregado de elaborar um parecer deferindo ou não uma solicitação de refúgio) e o solicitante de refúgio, no contexto das entrevistas de solicitação de refúgio no Comitê Nacional para Refugiados (Conare), órgão do Ministério da Justiça brasileiro encarregado dos processos de refúgio no país.

Para conduzir esse estudo, assentou-se em preceitos oriundos da sociolinguística interacional, desenvolvidos por John Gumperz e Erving Goffman (1998: 148), que sugerem que a interação constitui o principal fermento dos papéis sociais, obedecendo a princípios de coerência interna das relações interpessoais. Percebem-se as práticas verbais por meio das estratégias interativas e dos recursos discursivos de que lançam mão dos diferentes participantes na organização geral da interação:

A pesquisa que mostra como sinais relacionais funcionam para sinalizar atividades e tarefas discursivas, como as interpretações são acordadas e alteradas no curso de uma interação por meio de diferencialmente colocar em primeiro plano, subordinar ou concatenar várias informações que carregam elementos, é uma tarefa fundamental da sociolinguística interacional (1998: 209, tradução nossa) ${ }^{1}$.

Os dados foram coletados por meio de uma pesquisa de campo² em 2018 a partir de uma observação participante, trazendo uma análise qualitativa de estratégias discursivas dos intérpretes, que configuram seu papel de mediador e gestor.

Ressalta-se que a observação participante é um método de pesquisa etnográfica que visa alcançar a compreensão da situação em análise, por meio de uma imersão participativa no campo observado. Trata-se de uma forma de

\footnotetext{
${ }^{1}$ Original: Investigation showing how relational signs function to signal activities and discourse tasks, how interpretations are agreed upon and altered in the course of an interaction by differentially foregrounding, subordinating or concatenating various information carrying elements, is a major task of interactional sociolinguistics (1998: 209).

2 A pesquisa é descrita na parte 4 deste artigo.
} 
presença do pesquisador, que participa da situação enquanto um de seus agentes (VOGT 1999: 208).

Identificou-se nesses dados coletados e interpretados que a interpretação é percebida a partir de uma concepção idealizada, em que os agentes e manuais das instituições demandam do intérprete exatidão e fidelidade aos enunciados produzidos na língua-fonte, a exemplo do que é indicado no manual Metodologia e Técnicas para Entrevistar Solicitantes de Refúgio (ACNUR; DPU 2013, 13), usado pelos Oficiais de Elegibilidade no Conare, e que será discutido mais à frente.

Tal expectativa vai de encontro à concepção de tradução oral e de interpretação enquanto processo complexo que não pode ser apreendido exclusivamente em termos de transmissão de mensagem (HALE 2007: 25; PöCHHACKER 2004: 56). Na reescritura que o ato pressupõe, e que ganha sentido a partir da visada interativa, o tradutor/intérprete faz emergir algo que não existe nos enunciados, provocando uma mudança. Ao eleger construções na produção ou na reprodução de enunciados, ele os transforma e os adapta, trabalhando para que exista um lugar adequado, uma "potencialização" do discurso de partida. O sentido que ele produz é, portanto, o resultado de uma negociação entre práticas intersubjetivas. Em uma interação dialógica, como afirma Wandesjö (1995), o intérprete é confrontado com a dualidade de falar e ouvir pelos outros, devendo também intuir como os interlocutores desejam que suas falas sejam entendidas. Ciente da responsabilidade de mediar um diálogo com influência decisiva para o solicitante, o intérprete busca constantemente avaliar como gerenciá-lo. Os resultados das análises revelam estratégias discursivas às quais recorrem os intérpretes para mediar a interação e alcançar um resultado que julgam mais adequado às especificidades do evento de interação.

Para discutir essa questão, optou-se por iniciar a reflexão com uma síntese do contexto migratório no Brasil, com ênfase na situação dos refugiados; depois, discute-se a figura do chamado “intérprete comunitário” e de seu papel de mediador na situação de interação ora em análise; enfim, antes de apresentar os dados e as análises que levaram aos resultados da pesquisa, abordam-se conceitos levantados acerca da tradução/interpretação e de suas 
concepções, que coam com as questões levantadas pela situação sociolinguística observada.

\section{Contexto do refúgio no Brasil}

Um refugiado é uma pessoa que precisou fugir seu país de origem "devido a fundados temores de perseguição por motivos de raça, religião, nacionalidade, grupo social ou opiniões políticas [ou] devido a grave e generalizada violação de direitos humanos” (BRASIL, 1997), como no caso de guerras. O Alto Comissariado das Nações Unidas para os Refugiados (ACNUR) afirma que, até o final de 2018, havia 25,9 milhões de pessoas refugiadas no mundo e 3,5 milhões de solicitantes de refúgio (UNHCR 2019).

O Brasil, até dezembro de 2018, havia reconhecido o status de refugiado apenas para um total de 11.231 pessoas (MINISTÉRIO DA JUSTIÇA 2019: 7). Porém, o número de solicitações de refúgio tem crescido exponencialmente nos últimos anos e, em 2020, temos um total de 39.546 refugiados reconhecidos no país (MINISTÉRIO DA JUSTIÇA 2020) e mais de 200 mil solicitações de reconhecimento da condição de refugiado em trâmite (MINISTÉRIO DA JUSTIÇA 2020). 94\% dos refugiados reconhecidos são oriundos da Venezuela, que migraram devido à crise política, econômica e humanitária que assola o país, o que corresponde a 34 mil venezuelanos. Em segundo lugar, está a Síria, com 1.214 sírios refugiados no país.

A lei que rege o refúgio no Brasil é a $n^{\circ}$ 9.474/1997, que, além de determinar os critérios brasileiros para aceite ou não da condição de refugiado, também prevê os procedimentos para tal processo. Essa lei decretou a criação do Comitê Nacional para os Refugiados (Conare), órgão do Ministério da Justiça responsável por: analisar e reconhecer os pedidos de refúgio em primeira instância; decidir a cessação da condição de refugiado; determinar a perda da condição de refugiado; orientar e coordenar as ações para a proteção, assistência e apoio jurídico aos refugiados; aprovar instruções normativas para a execução da Lei $n^{\circ}$ 9.474/1997. O Conare é composto por representantes de sete órgãos, tanto governamentais quanto não-governamentais, quais sejam: 
Ministério da Justiça, Ministério das Relações Exteriores, Ministério do Trabalho, Ministério da Saúde, Ministério da Educação e do Desporto, Departamento da Polícia Federal e Alto Comissariado das Nações Unidas para Refugiados, este, embora tennha direito a voz, não tem voto (BRASIL 1997).

Para realizar a solicitação de refúgio no Brasil, gratuita, o migrante preenche um Termo de Solicitação de Refúgio. Munido do protocolo de solicitação, todo solicitante de refúgio goza dos mesmos direitos de um refugiado reconhecido, tal como a emissão de CPF e carteira de trabalho (BRASIL, 1997). Quando o processo chega ao Conare, é marcada uma entrevista com o oficial de elegibilidade do órgão, uma das etapas centrais do processo, sendo a história de vida do migrante um dos fatores decisivos para o reconhecimento de sua condição de refugiado. Nela, o solicitante fornece fatos relevantes para a análise de sua situação, que serão avaliados pela instância competente do Estado. Vale notar que, como muitos saem de seus países sem documentação ou sem provas físicas das violências ou da perseguição que sofreram, "se a declaração do requerente parecer crível, deverá ser concedido ao solicitante o benefício da dúvida, a menos que existam boas razões para pensar o contrário" (ACNUR 2011: 49-50), já que "a determinação do status de refugiado está vinculada a um elemento subjetivo e pessoal (o temor de perseguição) e a um elemento objetivo (fundamento de tal temor)" (LIMA ET AL 2017: 89). Ou seja, o papel da entrevista com o oficial de elegibilidade no processo de solicitação de refúgio é, de fato, crucial, por ser esse o momento em que o requerente tem a oportunidade de narrar sua história a partir de seu ponto de vista. Os oficiais também averiguam os fatos históricos, políticos e sociais do país de origem do solicitante para, então, tomarem uma decisão.

Uma vez concluída a entrevista, o oficial de elegibilidade elabora seu parecer, produzindo um resumo do que foi dito e sugerindo o deferimento ou indeferimento da solicitação. 0 processo é analisado por funcionários dos órgãos constituintes do Conare que corroboram ou não os pareceres dos oficiais. Por fim, os processos são submetidos à apreciação dos representantes desses órgãos em uma reunião plenária, onde conferem seu deferimento ou indeferimento por meio de ato declaratório (BRASIL: 1997). Por fim, os solicitantes são notificados da decisão do Conare e, em caso de indeferimento, 
têm quinze dias para entrar com um recurso e manter seu protocolo aberto. Caso não o façam, precisam buscar outras formas de permanência no país, ou correm o risco de ficar em situação irregular.

Toda mudança, em especial a de país, do próprio lar, é caracterizada por estranhezas e dificuldades e, embora o Brasil seja conhecido por seu caráter "acolhedor", os imigrantes e principalmente os refugiados vêm enfrentando diversas dificuldades de integração na sociedade brasileira. De acordo com o mapeamento do Instituto de Pesquisa Econômica Aplicada (IPEA), "no acesso a direitos como saúde, educação e justiça, [...] além de moradia e documentação, o idioma se mostra como a principal dificuldade enfrentada pelos migrantes" (OLIVEIRA; SILVA 2017: 132). As questões linguísticas, para além do aspecto prático da comunicação com os nativos do país, também são intrínsecas à questão identitária dos falantes

[...] como um significante da identidade e do pertencimento cultural, a língua frequentemente existe em conflito, contradições e ambiguidade em relação às expectativas e demandas de se viver em uma sociedade como um todo. Isso está relacionado à escolha dos estilos de vidas e das múltiplas identidades adotadas por indivíduos ou grupos de pessoas vivendo em diferentes sociedades como parte do processo de auto definição (RASSOOL 1998: 95, tradução nossa ${ }^{3}$ ).

Com efeito, as práticas linguísticas nos diferentes contextos e eventos comunicativos marcados pelos contatos de línguas se materializam em expressões de conflito, de discriminação e de subordinação, além de gerar processos variados de resistência (HAMEL 1995: 79). De acordo com Hamel (1995), encenam-se, nos eventos cotidianos, rupturas entre as práticas linguísticas e os modelos culturais de referência (HAMEL 1995). Tais processos ameaçam os direitos linguísticos dos sujeitos e seu diálogo com a sociedade de acolhimento, que acaba por não os acolher de fato, especialmente no que se refere aos direitos e à justiça. Como afirma o chefe do ACNUR, Filippo Grandi, é necessário que haja um aprimoramento na busca por soluções para que

\footnotetext{
${ }^{3}$ Original: "[...] as a signifier of identity and cultural belonging, language often exists in conflict, contradictions and ambiguity in relation to the expectations and demands of living within society as a whole. This is related to the choice of lifestyles and multiple identities adopted by individuals or groups of people living in different societies as part of the process of self-definition."
} 
"refugiados, deslocados internos e apátridas reivindiquem ou adquiram um total pertencimento à sociedade e construam um futuro estável" (MARQUEZ 2017: 10).

No Brasil, o acesso à justiça dos migrantes e refugiados tem sido usurpado pela ausência de mediação linguística entre o solicitante de direito e o agente do estado, cujo papel seria avaliar a solicitação para deferi-la ou não. Nesse contexto, a avalição da solicitação pauta-se na narrativa produzida pelo solicitante, em que conta sua história num suposto diálogo com o agente público. Essa mediação, contemplada constitucionalmente, deveria ser assumida por um profissional capacitado e contratado para tal fim pelo estado: o intérprete comunitário, que atua em contextos diversos (jurídico, enquanto intérprete forense, médico, educacional, etc.). Essa não é a realidade, especialmente à luz do que ocorre nos fóruns de tribunais: "os 'intérpretes forenses' são, na mais das vezes, pessoas conhecidas dos juízes ou servidores do Judiciário, com conhecimento do português e de alguma língua estrangeira" (ALMEIDA; NoRDIN 2017: 485). Os autores narram a precariedade da situação dos intérpretes que atuam nas varas de Guarulhos, afirmando que "não há prova de seleção, exigência de comprovação de competência linguística ou entrevista prévia padronizada" (ALMEIDA; NORDIN 2017: 485).

No caso do processo de solicitação de refúgio, que no Brasil não é judicializado, a Cartilha para Solicitantes de Refúgio no Brasil (produzida pelo ACNUR em parceria com o Conare) afirma que o solicitante tem direito a um intérprete, embora não caiba ao governo fornecer esse serviço, e sendo de responsabilidade do imigrante vir acompanhado por um. Vale destacar que não há intérpretes comunitários profissionais, ainda menos funcionários públicos, nem mesmo verba para a contratação de seus serviços.

Com efeito, a despeito dos inúmeros inconvenientes da situação, os intérpretes que atuam no Conare, sempre voluntários, são geralmente outros imigrantes que já obtiveram o status de refugiado, ou algum membro da comunidade do país de origem do solicitante no Brasil. Não haver "intérpretes e tradutores qualificados a essa população em contextos críticos impede que esses indivíduos tenham acesso a recursos e serviços fundamentais para sua segurança e bem-estar" (OLIVEIRA; SILVA 2017: 135). 
Ao contrário de alguns países que já reconhecem a centralidade dessa ação, o Brasil, em suas instituições, muito lentamente vem se preocupando com a integração linguística dos imigrantes. O Peru, por exemplo, desde 2011 editou leis que amparam a promoção de formação e certificação de intérpretes e tradutores das línguas indígenas do país (KLEINERT ET AL 2019: 86). No ano de 2020, o Ministério da Cultura peruano lançou uma convocação para o $14^{\circ}$ Curso de Intérpretes e Tradutores de Línguas Indígenas para serviços públicos (Ministério da Cultura, 2020). O Canadá, por sua vez, conta com um Conselho de Imigração e Refúgio, responsável por fornecer intérpretes para todos os migrantes que não falam francês ou inglês, além de exigir que os intérpretes passem em um teste de credenciamento (salvo em casos excepcionais, quando o solicitante fala uma língua muito rara). Outro exemplo é a Austrália, que, além de ter cursos universitários voltados para a Interpretação Comunitária, oferece, em nível governamental, um serviço gratuito de interpretação comunitária para cidadãos e residentes em contextos médicos, jurídicos, farmacêuticos, entre outros (REFUGEE COUNCIL 2013).

Frente ao vácuo e à ausência de políticas públicas de acessibilidade linguística no Brasil, esse papel tem sido principalmente exercido pelas organizações não governamentais e religiosas (REFUGEe CouncIL 2013: 144), e universidades, a exemplo do trabalho, citado acima, desenvolvido pelo grupo de pesquisa MOBILANG da Universidade de Brasília. O grupo implementou em 2014 o projeto de Extensão "Migrações e fronteiras no Distrito Federal: a integração linguística como garantia dos direitos humanos", cujo objetivo central é prover apoio linguístico à população imigrante no Distrito Federal (Brasília) em sua relação com as instituições públicas que administram os processos migratórios no país.

\section{Interpretação comunitária}

No fim do século passado, o cerne dos Estudos da Interpretação recaía na interpretação simultânea e de conferência, como resultado de uma demanda das redes internacionais de cooperação (PRUNC 2012: 3). São modalidades que 
raramente encenam um contato direto entre o intérprete e os interlocutores, o foco do trabalho recaindo quase que exclusivamente na mensagem enunciada e traduzida. Porém, com a intensificação das migrações no século XXI, a modalidade da interpretação comunitária tem ganhado visibilidade, uma vez que é atividade requerida em contextos de serviço público, hospitalares e jurídicos (PöCHHACKER 2004: 15), e "serve àqueles que vêm de outros países, imigrantes ou o que buscam asilo político" (ORIGUELA 2014: 226) a fim de se comunicarem e acessarem direitos.

Importa notar que essa modalidade recebe diferentes denominações de acordo com os países e contextos, sendo conhecida por “legal interpreting, court interpreting, public service interpreting, contact interpreting, dialogue interpreting, interpretación social, interpretación de enlace, etc" (ORTEGAHERRÁEz 2004: 2), o que reflete os diversos focos acerca da atividade. No Reino Unido, por exemplo, predomina a denominação de "public service interpreting" (PöCHHACKer 2004: 15); termo também usado no Peru (KLEINERT ET AL, 2019: 83). Se o termo 'interpretação no serviço público' se concentra no ambiente em que essa atividade se faz necessária, o de 'interpretação dialógica' foca na interação entre os participantes.

Trazendo um enfoque no fato de ser um serviço prestado à comunidade, no Brasil, o termo mais disseminado é o da interpretação comunitária, assim apontado em currículos acadêmicos e cursos de especialização ${ }^{4}$. Vale ressaltar que o conceito é bastante amplo, abrangendo inclusive a interpretação forense e de Língua de Sinais Brasileira - Libras (RodRIgues 2010: 7).

Tal modalidade caracteriza-se pela variedade de línguas minoritárias em contato, em contraste com os contextos da diplomacia internacional; a presença explícita do intérprete em interações dialógicas; e o papel social do intérprete (METIN 2015: n.p.), que determina em grande medida o destino de uma pessoa em situação de vulnerabilidade (UNHCR 2017: 27).

Há muitas frentes de pesquisa sobre interpretação comunitária, como avaliação de qualidade, análise textual das transcrições das interações, tecnologia, terminologia, ética, entre outras (VARGAS-URPI 2012: 51). No

\footnotetext{
${ }^{4}$ Por exemplo, o curso de graduação de Tradução e Interpretação da Uninove contém em seu currículo a disciplina de Interpretação Comunitária; também há o Curso de Interpretação Comunitária e de Conferência de Libras da Universidade Federal de Goiás.
} 
entanto, Sandra Hale afirma que existe um vácuo na reflexão sobre Interpretação Comunitária quanto à formação do intérprete, tanto pela falta de reconhecimento da sua necessidade, quanto pela ausência de programas de treinamento adequados e efetivos (HALE 2007: 163). Pochkkacker (2004: 32) ratifica a importância de existirem publicações sobre a interpretação (em especial a comunitária) para que se divulgue o conhecimento especializado sobre a profissão, porque

o reconhecimento da interpretação enquanto profissão pressupõe que há um corpo de conhecimentos e habilidades especializados que são compartilhados por seus atuantes. Essa competência profissional, inicialmente desenvolvida por meio da experiência e reflexão, precisa ser exteriorizada e explicitada, tanto para representar (e apresentar) a profissão às outras pessoas na sociedade quanto para dar suporte ao treinamento dos futuros profissionais (tradução nossa) ${ }^{5}$.

Com foco em refúgio, o ACNUR oferece alguns módulos de estudos individuais pela internet e algumas cartilhas, ainda que caiba aos órgãos responsáveis pela migração e refúgio de cada país fornecer treinamentos a seus intérpretes (UNHCR 2017: 39). No contexto de refúgio, há intérpretes certificados e com treinamentos completos, intérpretes com pouco treinamento e intérpretes completamente amadores (UNHCR 2017: 39). Um dos motivos, além da falta de incentivo e demanda por parte dos órgãos governamentais que lidam com refúgio, é a impraticabilidade de oferecer treinamento para línguas minoritárias, cuja demanda aparece recorrentemente. Para esses casos, contam com os serviços de intérpretes com pouco treinamento ou amadores (UNHCR 2017), como é o caso do Brasil. Essas lacunas revelam a ausência de políticas linguísticas destinadas à inserção das populações migrantes na sociedade local, ainda que os documentos e leis assim o prevejam. A Cartilha para Solicitantes de Refúgio no Brasil indica que a entrevista de solicitação de refúgio deve ser feita "num idioma que [o solicitante] compreenda e, se necessário, [ele] tem direito a um intérprete"

\footnotetext{
${ }^{5}$ Original: "The recognition of interpreting as a profession implies that there is a body of specialized knowledge and skills which is shared by its practitioners. This professional expertise, which is initially developed through experience and reflection, needs to be externalized and made explicit, both for (re)presenting the profession to others in society and in support of the training of future practitioners."
} 
(ACNUR s/a: 15). Além disso, os oficiais de elegibilidade, a cada entrevista, devem passar as instruções aos intérpretes, retiradas do manual intitulado "Metodologia e técnicas para entrevistar solicitantes de refúgio", preparado pela Defensoria Pública da União e pelo ACNUR. O manual, que pretende conter todas as informações necessárias para as entrevistas, incluindo uma seção destinada à preparação do intérprete, indica que o oficial deve instruir o intérprete a ser

neutro e objetivo durante o processo de entrevista. [E que os intérpretes] devem entender que tudo o que o entrevistador e o solicitante digam deve ser traduzido. Não é suficiente resumir ou embelezar o que é dito, fornecendo informações que faltam. $O$ intérprete não deve melhorar as palavras do solicitante para torná-lo mais consistente, confiável e educado (DPU; ACNUR 2013: 13, grifos nossos).

Diante de tais orientações, questiona-se a que se refere o manual por termos como "embelezar" e "melhorar". Também sugere que o intérprete deva ser "fiel" aos enunciados produzidos pelo solicitante, conceito peremptoriamente questionado pelos Estudos da Tradução e que parte do pressuposto de que as palavras possuem "equivalentes" de uma língua para outra, premissa objeto de amplas problematizações. O manual também prescreve que o entrevistador deva encerrar a entrevista caso esteja insatisfeito com a qualidade da tradução oral, e ficar atento à relação entre o solicitante e o intérprete para que "estejam à vontade um com o outro" (2013: 13). Importa então questionar sob quais parâmetros e a partir de qual visão essas orientações são ditadas?

\section{O intérprete comunitário como mediador/}

\section{agente social}

Focamos aqui no papel do intérprete cuja agência social é fundamental para e pela interação social. A interpretação é tida como uma "inter-atividade" (WANDESJÖ 1995: 112), uma ação que trespassa a função linguística, tendo o intérprete um papel de intervenção que remete mais a de agente social do que 
de agente de inteligibilidade linguística. Angelelli (2004: 27) afirma, de fato, que é necessário considerar o evento comunicativo da interpretação como um evento social ou político. Se muitos trabalhos focam fundamentalmente no estudo do texto em vez do estudo do tradutor (PYM 2006: 2), nos Estudos da Interpretação, por outro lado, a atenção no mediador é fundamental, uma vez que a interpretação tem sido entendida como uma prática social, o que implica enxergar o tradutor enquanto mediador, entendendo de quem e para quem interpreta, dentro de quais contextos e quais os efeitos sociais de sua agência (PYM 2006: 4).

Antes, porém, questiona-se a própria noção de mediação. Pöchhacker (2008: 10), já relacionando mediação com interpretação, busca defini-la a partir da função de intermediação, que sugere que um tradutor/intérprete é agente de um processo cujo objetivo não abarca necessariamente uma redução de conflitos. A tradução oral não é apenas uma mediação interlingual, mas também intercultural ( PöCHHACKER 2008: 11), pois o intérprete se vê diante de dois espaços que ele precisa conectar. Em si mesmo está um amálgama das duas culturas que, através de um processo tradutório, se expande aos demais interlocutores.

Justamente por a interpretação ser uma interação interpessoal fortemente estruturada pelas práticas linguísticas, é necessário levar em conta as variáveis da interação, pois, tal como afirma Angelelli (2004: 27), "uma perspectiva social e sociológica nos permitiria explorar a agência ou o poder que o intérprete tem" (tradução nossa) ${ }^{6}$. Os conhecimentos extralinguísticos, como o conhecimento sobre a situação política do país ou o conhecimento de como as entrevistas se organizam, por exemplo, também são fatores a serem considerados em relação ao intérprete comunitário, seja ele profissional ou amador.

Vale também novamente ressaltar que o intérprete é a única pessoa a entender tudo o que é enunciado pelos participantes, tendo uma visão geral da interação e, assim, coordenando-a (WANDESJÖ 1995: 112-113). Ou seja, torna-se o participante pivô, com a responsabilidade de hierarquizar as informações de

\footnotetext{
${ }^{6}$ Original: "a social and sociological perspective would allow us to explore the agency or the power that interpreters hold".
} 
e para ambos os lados. Com isso, entende-se a que Blume e Peterle (2013: 11) se referem quando declaram que um tradutor é um "negociador", "mesmo que essas ações sejam inconscientes e aparentem ser 'imediatas'. É durante essa negociação que as relações e as tensões relativas ao poder são estabelecidas".

Wandesjö (1995: 113) levanta dois aspectos importantes da atividade do intérprete, que são simultâneos e complementares: "O discurso do intérprete deve ser analisado tanto como uma retransmissão ou tradução e como uma coordenação e mediação" (tradução nossa, grifos da autora) ${ }^{7}$. Tendo isso em mente, Wandesjö (1995: 114) entende as práticas linguísticas como atividade social, em que o sentido é construído em conjunto entre o falante e o ouvinte em interação. É possível entretanto que, ainda que se trate de uma interação supostamente monolíngue, haja incompatibilidade nas expectativas e nos repertórios sociolinguísticos presentes nas perguntas e respostas de ambos os interlocutores.

De acordo com o ACNUR (2017: 27) da Áustria, muitos Estados-Membros da União Europeia definiram o Método de Comunicação Dialógica (MCD) como o padrão para as técnicas de entrevistas em casos de refúgio. Apesar de ter sido criado com o propósito de entrevistar crianças e, mais tarde, vítimas ou testemunhas de casos de violência, o MCD atualmente é usado para todas as entrevistas de solicitações de refúgio (UNHCR 2017: 27). Pautam-se na ideia de entrevista-diálogo, caracterizada por um modo empático de comunicação, isto é, não se assemelhando a um interrogatório, em que os métodos usados garantam a coleta de informações relevantes e completas (UNHCR 2017: 28). Dessa forma, é necessário criar um ambiente amigável entre os participantes, incluindo, obviamente, o intérprete, de modo que o solicitante responda às perguntas e possa contar sua história de forma livre. Até a posição dos assentos na sala deve ser levada em consideração: essa deve preferencialmente formar um triângulo, em que cada participante fique em uma ponta, com as mesmas distâncias entre si (UNHCR 2017: 29).

Há, portanto, uma carga de responsabilidade social que pesa sobre o intérprete comunitário e que leva autores a sugerirem que se trata de uma

\footnotetext{
7 Original: "The interpreter's discourse has to be analysed both as relaying or translating and as coordinating or mediating".
} 
atividade que combina interpretação e assistência social (HALE 2007: 26). Essa visão é corroborada por Wadensjö (1995: 115), quando afirma que "o intérprete é contratado não por uma pessoa ou uma empresa, mas pela sociedade" (tradução nossa) $^{8}$, o que levanta a questão da "lealdade" do intérprete comunitário e a quem ela se deve.

Na Suécia, foi conduzida uma pesquisa por Carsetensen e Dahlberg (2017: 51), em que juízes e advogados foram questionados sobre quais as características de um bom intérprete. Eles responderam que é aquele que não é visto nem notado, cuja presença e agência são invisíveis, percepção compartilhada pelos oficiais de elegibilidade do Conare. Em contraponto, os intérpretes entrevistados enfatizaram a ideia de que precisam ocupar uma posição no ambiente, interromper, fazer perguntas, exigir pausas e apontar erros.

O ACNUR da Áustria criou, em 2017, um Handbook for Interpreters in Asylum Procedures, uma vez que não há um regulamento internacional para a profissão. Embora a capa apresente uma citação contundente de um intérprete onde se lê "É uma ficção que eu sou neutro e invisível” (UNHCR 2017: 1), o manual indica que o intérprete deve sempre se manter imparcial, sem expressar nenhuma opinião pessoal ou omitir informações que favoreça alguma das partes (UNHCR 2017: 42). Defende ainda a profissionalização e treinamento dos intérpretes comunitários, em especial daqueles que trabalham com refugiados, listando uma série de competências e atributos do intérprete ideal: ser criativo e autocrítico; ser empático com o desconhecido; ser flexível; saber trabalhar em equipe; ter boa memória; entre diversos outros atributos (UNHCR 2017: 43). O que se demanda de um intérprete vai portanto muito além das competências linguísticas para que seja produzida "uma interação ideal”, ressaltando-se aqui a exigência de criatividade, cuja característica é justamente a capacidade de inovar e transformar.

Para além da função de traduzir, o intérprete comunitário também tem a responsabilidade de coordenar e mediar a interação. Angelelli argumenta que as intervenções dos intérpretes, sua "visibilidade", são resultados das relações dos fatores sociais, já que "os comportamentos dos intérpretes são impactados

\footnotetext{
8 Original: "the interpreter is hired not by one person or a company, but by a society".
} 
tanto pela realidade da situação onde a interpretação ocorre quanto pelas realidades de cada um dos interlocutores” (2004: 29, tradução nossa ${ }^{9}$ ).

O Manual do ACNUR aborda as implicações de o intérprete comunitário também trabalhar como um mediador cultural, uma vez que os intérpretes

\begin{abstract}
Sabem e conseguem identificar os conceitos e referências específicos da cultura e estão cientes dos comportamentos culturalmente determinados que podem ser mal interpretados; chamam a atenção dos participantes para os conceitos específicos da cultura que podem levar a mal entendidos; pedem que um participante explique conceitos e referências específicas da cultura e depois as interpretem para os outros participantes; buscar esclarecimentos caso sintam que não tenham entendido (por completo) os participantes devido às expressões e conceitos específicos da cultura.

[Porém, é importante ficar claro que] Mediação cultural NÃO QUER DIZER que os intérpretes intervenham a fim de darem suas próprias opiniões ou comentários, e julguem como "correto" ou "incorreto" algum comportamento determinado culturalmente de algum participante. Se o intérprete pede por esclarecimento, ele deve informar todos os participantes das perguntas feitas e das respostas dadas. (UNHCR, 2017, p. 53. Grifo do autor. Tradução nossa) ${ }^{10}$
\end{abstract}

Tal enunciado reafirma a ideia de que o papel do intérprete não é unidimensional. Ele é confrontado com a dualidade de falar e ouvir em nome dos outros, além de ter que avaliar como e por quem os falantes querem que seus discursos sejam entendidos (WADENSJÖ 1995: 120). Ele precisa, então, apreciar a posição e a relação entre os interlocutores, se posicionar diante dessa interação e intermediá-la. Nessa dialética, na qual o tradutor lê e interpreta o discurso do outro, em uma língua outra para enunciar o seu, sua posição é ambivalente. Ele se faz presente nessa fronteira entre outros, no momento em que sua atividade torna manifesto algo que seria inerente ao texto

\footnotetext{
${ }^{9}$ Original: “interpreters' behaviors are impacted by both the reality of the situation where interpreting occurs and the realities of each of the interlocutors".

${ }^{10}$ Original: "[...] know and can identify culture-specific concepts and references and are aware of culturally determined behavior that may be misread; draw participants' attention to culture-specific concepts that may give rise to misunderstanding; ask a participant to explain culture-specific concepts and references and then interpret these for the other interactant(s); seek clarification if they feel that they do not (fully) understand interactants because of their use of culture-specific expressions and concepts."

[However, it must be made clear that] Cultural mediation DOES NOT MEAN that interpreters intervene to offer their own opinion or comment and pass judgement on whether an interactant's culturally determined behavior is "correct" or "incorrect". If interpreters ask for clarification, they need to inform all participants about the questions they have posed and answers they have received".
}

TradTerm, São Paulo, v.36, dezembro/2020, p. 72-101 www. revistas.usp.br/tradterm 
de partida, colocando-se entre dois espaços, com um olho voltado para trás e outro para frente, efetuando desse modo uma operação de duplo sentido: observa em si mesmo o discurso do outro, e o outro em seu próprio enunciado.

Dessa forma, quando os intérpretes recorrem a estratégias para possibilitar a interação, "eles se fazem presentes e em sintonia com as realidades sociais das partes em interação" (ANGELELLI 2004: 29, tradução nossa $)^{11}$. Aliás, entrevistas são, por si só, situações caracterizadas por assimetrias explícitas de poder, em que o entrevistador domina, pois detém a autoridade de definir seus termos, seu início e seu fim (KVAlE 2005: 93). Mas, essencialmente, o parecer do oficial determinará o rumo da vida do solicitante.

No caso do Conare, ainda que o manual Metodologia e Técnicas para Entrevistar Solicitantes de Refúgio recomende que se deva prezar pelo bemestar do solicitante, que nunca deve se sentir coagido, como se estivesse sendo interrogado (DPU; ACNUR 2013: 26), a interação se pauta em uma entrevista guiada por perguntas e modelos predeterminados devendo seguir um padrão.

Rudvin (2005: 162, 170), quando aborda a questão da assimetria de poder nas interações mediadas por interpretação comunitária, investiga como o intérprete confronta e negocia e lida com esses desequilíbrios por meio de estratégias discursivas, enquanto sujeito participante também em condição de ser afetado ou de afetar tal assimetria. Isso se manifesta particularmente em contextos em que pessoas em situação de vulnerabilidade dependem de agentes estatais para a concretização de seus status migratórios no país de acolhimento. Ao intermediar esses discursos assimétricos, que reafirmam relações sociais e políticas assimétricas, o intérprete, na função de organizador da interação, assume também uma posição política que vai muito além da produção linguística dos solicitantes. Existem ainda fatores que enfatizam tal assimetria. Hale (2007: 87) afirma que "seria irreal que membros dos tribunais esperassem que solicitantes de refúgio que foram vítimas de tortura se expressassem de forma coerente e bem estruturada"(tradução nossa) ${ }^{12}$. Assim, as narrativas produzidas, marcadas pelo medo e pela insegurança, são duplamente afetadas pelo desequilíbrio de poder, manifestado linguisticamente (HALE 2005: 165).

\footnotetext{
${ }^{11}$ Original: "they are presented and tuned in to the social realities of the parties at talk".

12 Original: "it would be unrealistic for tribunal members to expect asylum seekers who have been victims of torture to express themselves in a coherent, well-structured way."
} 
Dentre os desequilíbrios que caracterizam a relação, o intérprete goza do poder de ser o interagente capaz de compreender todos os participantes, tudo passando assim pelas lentes de sua própria experiência. Além disso, empoderase da habilidade de amenizar ou exponenciar elementos do discurso, assim como conflitos e tensões causados pelas assimetrias culturais (RUDVIN 2005: 171 172).

Tais pressupostos são ainda reafirmados por um outro estudo realizado por Berk-Seligson que revela que os intérpretes em tribunais buscam orientar advogados e juízes na formulação das perguntas, podendo afetar a conclusão do caso (HALE 2007: 95). São repetições e uso de marcadores de discurso, ou alteração nos "estilos" das produções discursivas das testemunhas, ora eufemizando, ora dramatizando as narrativas (HALE 2007: 96). Ao contrário, o intérprete pode também uniformizar os registros do relato. Tais ocorrências revelam o poder da agência do intérprete que, ao tomar decisões linguísticas, afeta a relação e a percepção entre os participantes da interação, podendo ainda inverter ou alterar a própria relação de poder configurada pelas instâncias em presença.

\section{A situação sociolinguística da entrevista de solicitação de refúgio no Conare}

A pesquisa fonte desse artigo foi realizada ao longo de 2018, e foram observadas dezesseis entrevistas com solicitantes de refúgio, presenciais e via Skype. As entrevistas costumam durar de uma a duas horas, a depender do grau de sensibilidade do caso e das dificuldades de interação linguística.

A fim de melhor apreender o ponto de vista dos oficiais de elegibilidade quanto ao serviço de interpretação e à função dos intérpretes durante a interação, foi aplicado um breve questionário, com cinco perguntas subjetivas ${ }^{13}$, que revelou que a maioria prefere entrevistas sem intérpretes.

\footnotetext{
${ }^{13}$ As perguntas referiam-se à percepção do oficial de elegibilidade sobre o papel do intérprete. Estas são: 1) Para você, o que é uma boa interpretação?; 2) O que se espera de um intérprete durante a entrevista de solicitação de refúgio?; 3) você já passou por alguma situação constrangedora com algum intérprete?;
} 
Afirmam que sua presença afeta o tempo das entrevistas, tornando-as mais longas e menos diretas, "causando ruídos na comunicação". Também revela um consenso quanto ao que seria uma "boa interpretação" e um "bom intérprete": os oficiais lançam sistematicamente mão de conceitos de "exatidão", "imparcialidade" e de "neutralidade", além de apontarem que intérpretes amadores "interferem de forma inapropriada", ao "adicionarem ou modificarem informações nas respostas". Um fator de preocupação externado pelos oficiais no questionário refere-se ao desconforto da presença de uma terceira pessoa na sala quanto ao relato do solicitante, sensível e doloroso.

Todas as entrevistas do Conare são gravadas pelo próprio órgão. Como contrapartida do acordo de cooperação assinado com a UnB, depois de assinar um termo de confidencialidade, foi autorizado o acesso aos áudios das entrevistas observadas presencialmente. Para a coleta dos dados, foram feitas transcrições de trechos de quatro casos emblemáticos por exemplificarem a atuação e a agência dos intérpretes nas entrevistas de solicitação de refúgio. Para o presente artigo, selecionamos do corpus um exemplo de cada estratégia tradutória.

Depois de transcritos, os dados foram analisados qualitativamente, a partir da delimitação de algumas categorias de estratégias tradutórias desempenhadas pelos intérpretes, que se contrapõem à expectativa dos oficiais de uma interpretação "exata", "neutra" e "fiel”, características também explicitadas pelos manuais oficiais que regem os processos de refúgio.

A partir dos áudios, foram identificadas ocorrências de intervenções dos intérpretes suscetíveis de serem sistematizadas e comparadas em casos distintos; com isso, foram transcritos os trechos dessas ocorrências, que compõem o corpus da pesquisa, e classificados em tabelas de dados para cada categoria de análise. Os dados revelam, como mencionado, que os papéis de intérprete e mediador se sobrepõem constantemente, tendo uma repercussão explícita no progresso e nos resultados da interação. A função de gestor se manifesta de formas diversas, tal como por meio de perguntas, explicações e reformulações em busca de um "resultado feliz" da interação, considerada

4) Quais as maiores dificuldades de se ter uma entrevista com intérprete?; 5) Quais as diferenças entre uma entrevista com intérprete e uma sem intérprete?. 
pelos interagentes como aquela em que foi criada uma relação de confiança entre as partes e em que as "informações necessárias foram comunicadas". Lembremos que Pöchhacker (2008: 13) ressalva que intervenções verbais para sanar dúvidas são vistas como aceitáveis, ainda que a mediação dessa natureza leve o intérprete a produzir "interferências" percebidas como "ultrapassando a mera tradução".

Trazemos três categorias de estratégias características das interações observadas nessa pesquisa, com base na observação participante, tal como foi definida na introdução, e numa análise qualitativa das seguintes categorias: adição explicativa, quando explicitam algum fato, adicionando informações aos enunciados dos interlocutores; apropriação da autoridade do discurso, quando o intérprete assume a responsabilidade de responder às perguntas do oficial, sem que o solicitante o tenha feito; e gestão, nos momentos em que o intérprete revela estar administrando a entrevista. A categoria de "adição explicativa" foi cunhada por Pöchhacker (2008: 13); as outras duas, apropriação da autoridade do discurso e gestão, foram definidas pelas pesquisadoras a partir da especificidade dos dados coletados.

\section{Adição Explicativa}

O trecho ${ }^{14}$ abaixo foi extraído da entrevista de solicitação de refúgio de uma mulher síria, entrevistada com o auxílio de um amigo pertencente à sua comunidade, que já havia atuado como intérprete no Conare junto a outros conhecidos sírios. Ainda que familiarizado com o protocolo das entrevistas e tendo sido instruído pelo oficial em início de entrevista ("ser imparcial, sem tentar ajudar ou prejudicar a solicitante, sem acrescentar ou mudar o que foi dito”), nesse exemplo, o intérprete extrapola sua suposta função, ao elucidar fatos suscetíveis de convalidar a solicitação da solicitante.

\footnotetext{
${ }^{14}$ As entrevistas são divididas em duas partes principais: a primeira, na qual o oficial faz perguntas sobre a solicitante (idade, pais de origem, línguas etc.) e a segunda, na qual a solicitante narra seu relato e o oficial faz perguntas de acompanhamento. $O$ trecho em questão acontece na segunda parte.
} 
Oficial [para a solicitante]: A senhora em algum momento pediu refúgio pro governo da Jordânia, quando a senhora estava lá?

Intérprete pergunta em árabe para a solicitante.

Solicitante [para o oficial]: Não.

Oficial [para a solicitante]: Não? Tá.

[Pausa]

Intérprete [para o oficial]: Eu tenho uma informação, pode falar? Pelo causa do... não dela... da Jordânia.

Oficial [para o intérprete]: hum... tá, tudo bem.

Intérprete [para o oficial]: Lá, não tem refúgio, não pode, entendeu?

Oficial [para o intérprete]: Tá, entendi.

A adição busca prover informações destinadas ao oficial. 0 intérprete toma para si a responsabilidade de selecionar as informações providas ao oficial sem a validação do solicitante. Tais enunciados corroboram com as premissas de Rudvin (2005: 162) sobre as assimetrias de poder, o autor focando em como o intérprete lida, confronta e negocia esses desequilíbrios, transformando-as em estratégias discursivas. Nesse caso, o intérprete, ao sentir que a ausência de algumas informações pode afetar o entendimento do oficial sobre a condição da solicitante e, consequentemente, seu processo, passa a atuar na entrevista em prol da solicitante, apropriando-se de seu local de fala para esclarecer a situação da solicitante.

Vale aqui retomar a fala de Angelelli citada anteriormente, quando afirma que a agência do intérprete é impactada pela realidade dos interlocutores (2004: 29). Com efeito, o trecho acima explicita a necessidade do intérprete de explicar a situação da Jordânia, fator esse diretamente relacionado com o contexto sociopolítico do qual a solicitante fugiu.

\section{Apropriação da Autoridade do Discurso}

A apropriação da autoridade do discurso ocorre quando o intérprete interage com alguma das partes (oficial de elegibilidade ou solicitante de refúgio), produzindo respostas ou perguntas no lugar de algum dos interlocutores. 0 exemplo aqui exposto é de uma entrevista realizada com um 
migrante de Bangladesh, que veio ao Brasil devido à situação política do país. Há dois grandes partidos políticos que disputam o poder, o Awami League, atualmente o partido eleito, e o BNP (Partido Nacionalista de Bangladesh). 0 trecho ${ }^{15}$ apresenta uma interação entre oficial e intérprete considerada inapropriada por excluir o solicitante da interação.

Oficial [para o solicitante]: Mas o senhor teve algum problema com membros do governo de Bangladesh, ou o senhor tinha problemas com membros da Awami League, porque são coisas diferentes. Uma coisa é ter problemas com membros do governo...

Intérprete [para o oficial]: Assim é tudo junto lá. Membros de governos, assim tudo funciona igual, entendeu? Se ele trabalha pra grupo... essas coisas... funciona assim.

Oficial [para o intérprete]: Eu ainda acho que são coisas diferentes. Uma coisa é o governo de Bangladesh, outra coisa é a polícia de Bangladesh. Outra coisa é a Awami League.

Intérprete [para a oficial]: A Awami League, sim. 0 governo é outra coisa.

Oficial [para o intérprete]: Ok. O que eu quero saber é se ele teve problemas com membros do governo, a polícia, agentes públicos...?

Nesse exemplo, o intérprete busca prover elementos sobre a situação política em seu país. 0 trecho revela a relativa validação por parte da oficial da apropriação da autoridade do discurso pelo intérprete. 0 diálogo ocorre apenas entre a oficial e o intérprete, excluindo o solicitante da interação. Nesse caso, a oficial busca elucidar seu ponto de vista para que o intérprete formule a pergunta ao solicitante da forma que ela deseja. Infere-se que a exclusão do solicitante da interação pode causar desconforto e insegurança ao entrevistado, amplificando sua sensação de vulnerabilidade, situação que não ocorreria se ambos oficial e intérprete tivessem sido capacitados e treinados para tal fim.

\footnotetext{
${ }^{15} \mathrm{O}$ trecho insere-se na segunda parte da entrevista, quando o solicitante relatava seus problemas com membros do partido opositor.
} 


\section{Gestão}

No exemplo abaixo ${ }^{16}$, o entrevistado, um egípcio que afirma integrar o grupo Seis de Abril, embora fosse capaz de interagir em português, foi acompanhado de um amigo mais fluente para auxiliá-lo linguisticamente. 0 entrevistado explica ao intérprete, em sua língua, algo a ser reportado ao oficial de elegibilidade. 0 intérprete orienta então o solicitante a falar a ele exatamente aquilo que ele deseja contar ao oficial.

Enquanto mediador da interação, o intérprete coloca os interlocutores em contato, trazendo à tona as relações, os discursos e as normas entre os dois. Dessa forma, o intérprete tem a agência de organizar e gerenciar a interação e os fenômenos linguísticos nela presentes. Diante da autoridade do oficial, o intérprete gerencia o diálogo de forma que a fala do solicitante seja percebida como integralmente traduzida ao oficial. Essa situação de interação convalida a hipótese de Gorovitz, quando sugere que o intérprete "torna explícitos os vínculos formais [...] entre dois discursos e entre as normas que se encontram, nesse momento, "em contato" e em tensão, [estabelecendo] relações de dependência ou de responsabilidade [...] entre os dois indivíduos" (2016: 3).

Oficial [para o solicitante]: Me explica então o que era esse grupo? O que era o grupo 6 de abril?

Solicitante [para o oficial]: Grupo para ficar liberdade, poder mais liberdade, e conseguir viver bem. Ah... eu não gostei muitas coisas meu lei... meu.. ah... posso explicar para ele [o intérprete] uma coisa em árabe? [O oficial consente].

[Solicitante fala em árabe com o intérprete.]

Intérprete [para o solicitante]: Não, você tem que falar para mim árabe tudo o que você quer falar português [solicitante interrompe falando em árabe], porque não pode falar coisas para mim.

Oficial: Sim.

\footnotetext{
${ }^{16} \mathrm{O}$ trecho refere-se ao início da segunda parte da entrevista, na qual o solicitante expõe os motivos de sua saída do Egito.
}

TradTerm, São Paulo, v.36, dezembro/2020, p. 72-101 www. revistas.usp.br/tradterm 
Nossa análise também se pautou nas orientações dos manuais desenvolvidos pelas entidades que regem os processos migratórios e de concessão de refúgio, tal como o da Acnur e DPU usado pelo Conare para a condução das entrevistas e que considera que a presença de um intérprete “constitui um obstáculo adicional para a comunicação" (2013: 13). Os dados revelam justamente que o intérprete, ainda que transgredindo aquilo que é esperado pelos manuais e instituições, funciona, ao contrário, como um facilitador da interação. Observa-se também que, apesar da exigência de padronização, cada entrevista apresenta suas peculiaridades que se moldam ao longo da situação de interação, em que os interlocutores envolvidos definem seu andamento por meio de ações e reações a cada novo estímulo interacional. Cada intérprete cria suas estratégias para gerenciar a interação, gerando reação do oficial. Tais estratégias são formas encontradas pelos intérpretes de contornar o que ele percebe como incongruências entre os discursos dos oficiais e dos solicitantes.

\section{Conclusão}

Analisar o papel do intérprete nas entrevistas de solicitação de refúgio implica apreender tanto as especificidades da interpretação comunitária quanto sua prática no Brasil, como uma forma de implementação de uma política linguística comprometida com a necessidade de participação de comunidades oriundas de fora. Como se viu, a interpretação comunitária é um tipo de serviço tradutório caracterizado pelo seu cunho social, em contextos jurídicos, migratórios, hospitalares, educacionais etc. Tais características fomentam o debate acerca dos desafios que as instituições enfrentam em fornecer esse serviço frente a uma crescente demanda. Trata-se de um direito do solicitante que o Estado não respeita, a falta de institucionalização acarretando a ausência de profissionalização e de reconhecimento da profissão e a reafirmação de preconceitos e juízo comum. Com efeito, e contrapondo-se a essa necessidade, resistências múltiplas projetam-se sobre a presença e a atuação do intérprete, considerada intrusiva. Como levantado pelas autoras Martin e Valero-Garcés (2008), a interpretação comunitária é uma das 
atividades em que a contradição entre o ponto de vista dos profissionais e da sociedade no geral se faz mais presente. Atestam que

(...) prevalece, em certos segmentos da sociedade (e nos manuais oficiais), infelizmente, a ideia de que a tradução e a interpretação são operações mecânicas de mudanças de códigos, nas quais literalidade se iguala a fidelidade [...] (VALERO-GARCÉs; MARTIN 2008: 3, tradução nossa) ${ }^{17}$.

De fato, as observações realizadas ao longo da pesquisa revelam que as expectativas dos oficiais enfrentam constantemente a própria lógica da interação, ou seja, as relações que se travam entre as práticas linguísticas em um contexto sociolinguístico onde o intérprete é o mediador, linguístico e cultural, de uma interação bi ou multilíngue. Exigir do intérprete uma tradução oral exata e fiel é associar a sua participação na interação como possivelmente isenta, presumindo que as línguas possam se constituir em sistemas fechados, com possibilidade de equivalentes, sejam quais forem os desafios da interação, desconsiderando-se assim o próprio fator humano de toda interação. A prática revela que a todo momento os intérpretes, pautados pelo contexto e pelas relações interpessoais, produzem atos tradutórios e linguísticos de reformulação e de expansão, que fogem à simples "transcodificação" esperada pelos interagentes.

No papel de mediador, o intérprete é também responsável por colocar dois estrangeiros um diante do outro, de "falar pelos outros e ao mesmo tempo ouvir em nome dos outros", tendo que "avaliar como, e por quem, os interlocutores pretendem que suas falas sejam entendidas" (WASDENJÖ 1995: 120). Ainda que confrontados com exigências de "imparcialidade" e de "não interferência" diante do discurso do solicitante (e do oficial), as relações sociais e de poder presentes na interação são fatores que marcam, mesmo inconscientemente, a produção linguística do intérprete. As estratégias implementadas pelos intérpretes como recursos de gerenciamento da interação e da relação entre oficial e solicitante corroboram a tese de que o intérprete é um agente ativo, mediador cultural e linguístico, cuja atuação precisa ser

\footnotetext{
17 Original: "However, for many in society at large, translation and interpreting are unfortunately considered as mechanical, code-switching operations in which literalness is equated with fidelity."
} 
reconhecida e oficializada pelas instituições envolvidas na implementação das políticas linguísticas voltadas para o acolhimento dos imigrantes no Brasil. Temos, então, um sistema que exige do intérprete um entendimento e uma competência incongruente com o que é oferecido pelos intérpretes voluntários e amadores, ao mesmo tempo em que esse mesmo sistema não fornece intérpretes qualificados nem treinamento. Estando nesse limbo, as instituições que atendem migrantes continuam perpetuando conceitos ultrapassados do que seja interpretação e tradução e do que se deve esperar do intérprete.

Se a implementação de políticas públicas para determinar a necessidade de uma mediação linguística qualificada, pautada em orientações e formação pertinentes, se faz urgente, é também de suma importância que essas orientações sejam definidas por pesquisas sobre o que é traduzir e interpretar e sobre os limites do que se espera, a priori, desses mediadores. Embora exista um manual de atuação destinado aos oficiais de elegibilidade do Conare, observa-se a ausência de protocolos direcionados àqueles que, compensatoriamente, se dispõem a assumir esse papel.

A presente reflexão se estabelece como ponto de partida para, a curto prazo, a formulação de protocolos e orientações, cujo enfoque recai sobre uma visão da interpretação e do papel do intérprete desenvolvida por especialistas dos Estudos da Tradução, capazes de refutar o senso comum que permeia os manuais atuais. Deve portanto guiar tanto o comportamento dos oficiais de elegibilidade, quanto o dos próprios mediadores. A médio prazo, é essencial definir competências e habilidades para desempenhar tal função, elencando os conteúdos constituintes de um currículo de formação.

Trata-se, assim, de contribuir para os estudos da interpretação comunitária de modo a contrariar a visão limitadora sobre o papel do intérprete em favor de um conhecimento compartilhado pelas instituições acadêmicas e aquelas envolvidas com o acolhimento e bem-estar dos imigrantes, refugiados e solicitantes de refúgio no Brasil. Busca-se, desse modo, validar o pressuposto de que toda tradução/interpretação desloca o discurso de partida, constituindo-se como desilusão em relação ao fantasma, tão almejado apesar de ilusório, da equivalência e da fidelidade. 


\section{Referências bibliográficas}

ACNUR, Manual de Procedimentos e Critérios para a Determinação da Condição de Refugiado [S.I.], 2011. Disponível em: <http://www.acnur.org/portugues/wpcontent/uploads/2018/02/Manual_de_procedimentos_e_crit\%C3\%A9rios_ para_a_determina\%C3\%A7\%C3\%A3o_da_condi\%C3\%A7\%C3\%A30_de_refugia do.pdf>. Acesso em: 19 maio 2018.

ALMEIDA, P. M. R.; NoRDIN, J. N. Interpretação forense: a experiência prática da Justiça Federal de Guarulhos e o treinamento de intérpretes. Ajufe, São Paulo, ano 30, n. 96, 2017, p. 481-520.

ANGELELLI, C. Revisiting the interpreter's role: a study of conference, court, and medical interpreter in Canada, Mexico, and the United States. Philadelphia: John Benjamins B.V, 2004.

BARRETo, L. P. A Lei Brasileira de Refúgio - Sua História. In: Refúgio no Brasil: a proteção brasileira aos refugiados e seu impacto nas Américas. $1^{\text {a }}$ ed. Brasília, DF: ACNUR, Ministério da Justiça, 2010.

Blume, R. F.; Peterle, P. Tradução e Relações de Poder. Tubarão: Copiart; Florianópolis: PGET/UFSC, 2013.

BRASIL. Lei $n^{\circ}$ 9474, de 22 de julho de 1997. Define mecanismos para a implementação do estatuto dos refugiados de 1951, e determina outras providências. Diário Oficial da República Federativa do Brasil, Poder Executivo, Brasília, DF, 23 jul. 1997.

DefEnSORIA PÚBLICA DA União; ACNUR. Metodologia e técnicas para entrevistar solicitantes de refúgio: módulo de capacitação. Brasília, DF: Defensoria Pública da União, 2013.

GOROVITZ, S. Editorial: Sociolinguística e Tradução. Belas Infiéis, Brasília, DF, v. 5, n. 2, pp. 1-6, 2016.

GUMPERZ, J. J. Contextualization and understanding. In: DURANTI, A. E GOODWIN, C. (Ed.). Rethinking context: language as an interactive phenomenon. Cambridge: Cambridge University Press, 1992. p.229-252.

GUMPERZ, J. J.. Convenções de contextualização. In: RibeIRo, B. T e GARCEZ, P. M. (Org.) Sociolinguistica Interacional. Porto Alegre: Age, 1998.

HALE, S. Community Interpreting. London: Palgrave Macmillan, 2017.

Hamel, R. E. Conflictos entre lenguas y derechos lingüísticos: perspectivas de análisis sociolinguístico, Alteridades, v. 5, n. 10, 1995, p. 79-88.

International Organization for Migration. World Migration Report 2018. Geneva: IOM, 2017. 
Kleinert, C. V.; Nuñez-Borja, C.; Stallaert, C. Buscando espacios para la formación de intérpretes para la justicia en lenguas indígenas em América Latina. Mutatis Mutandis, v. 12, n. 1, 2019, p. 78-99.

Kvale, S. The dominance of dialogical interview research. Implus, Bern, v. 1, pp. 89-105, 2005.

LIMA, J. B. B. et al.. Refúgio no Brasil: Caracterização dos perfis sociodemográficos dos refugiados (1998-2014). Brasília, DF: Ipea, 2017.

MARQUEZ, I. Prefácio. In: LIMA, J. B. B. et al. Refúgio no Brasil: Caracterização dos perfis sociodemográficos dos refugiados (1998-2014). Brasília, DF: Ipea, pp. 9-11, 2017.

METIN, E. Community Interpreting in the USA: Contributions of a Broad-based National Organization. M.A. dissertation, Istanbul University, Institute of Social Sciences. Translation Studies, 2015. Disponível em: <http://www.academia.edu/1734219/Community_Interpreting>. Acesso em: 30 ago 2018.

Ministério da Justiça e Segurança PúBliCA. Refúgio em números. Brasília, DF: Secretaria Nacional de Justiça; Conare, 2017. Disponível em: <http: / /www.acnur.org/portugues/wpcontent/uploads/2018/01/refugio-em-numeros-2010-2016.pdf >. Acesso em: 29 jun 2018.

Ministério da Justiça e Segurança Pública.. Refúgio em números: $3^{a}$ edição. Brasília, DF: Secretaria Nacional de Justiça; Conare, 2018. Disponível em: < http://www.casacivil.gov.br/operacao-acolhida/documentos/refugioem-numeros-3a-edicao-Conare-secretaria-nacional-de-justica-ministerioda-justica/view >. Acesso em: 29 jun 2018.

MinistéRIO dA JUSTIÇA E SEgURANÇA PÚBLICA.. Solicitantes de refúgio terão documentos de identificação no Brasil. Assessoria de Comunicação Social. Ministério da Justiça e Segurança Pública. Artigo de 6 de fevereiro de 2018. Disponível em: < http://justica.gov.br/news/solicitantes-derefugio-terao-documento-de-identificacao-no-brasil>. Acesso em: 04 de fevereiro de 2019.

Ministério dA JustiçA E SegurançA PúblicA.. Refúgio em números: $4^{\mathrm{a}}$ edição. Brasília, DF: Secretaria Nacional de Justiça; Conare, 2019. Disponível em: https://www.acnur.org/portugues/wpcontent/uploads/2019/07/Refugio-em-nu\%CC\%81meros_versa\%CC\%83o23-de-julho-002.pdf .

Oliveira, A. T. R. Nova lei brasileira de migração: avanços, desafios e ameaças. Revista Brasileira de Estudos de População. São Paulo, v. 34, n. 1, 2017, p. 171-179.

Oliveira, G. M.; Silva, J. I. Quando barreiras linguísticas geram violação de direitos humanos: que políticas linguísticas o Estado brasileiro tem 
adotado para garantir o acesso dos imigrantes a serviços públicos básicos? Gragoatá, Niterói, v. 22, , n. 42, 2017, p. 131-153.

ONU. Convenção Relativa ao Estatuto dos Refugiados. Resolução n. 429 (V) da Assembleia Geral das Nações Unidas, de 14 de dezembro de 1950. Séries Tratados da ONU, $\mathrm{N}^{\circ}$ 2545, Vol. 189, 1954. Disponível em: $<$ https://www.acnur.org/fileadmin/Documentos/portugues/BDL/Conven cao_relativa_ao_Estatuto_dos_Refugiados.pdf > Acesso em: 22 abr 2019.

ORIGUeLA, D. Interpretação Comunitária, Direitos Humanos e Assistência Social: proposta de política pública no contexto brasileiro. TradTerm, São Paulo, v. 23, Set/2014, p. 225-240.

Ortega-Herráez, J. M. Hacia una mayor calidad formativa en interpretación judicial. Calidad y Traducción. Perspectivas académicas y profesionales. Madrid: Universidade Alfonso X El Sabio, 2004.

PöCHHACKER, F. Interpreting as mediation. In: Valero-Garcés, C.; MARTIN, A. (Ed.). Crossing Borders in Community Interpreting: definitions and dilemmas. Amsterdam: John Benjamins, pp. 9-26, 2004.

PYM, A. On the social and cultural in translation studies. In: PYM, A.; SHLESINGER, M.; JetTMAROvÁ, Z. (Ed.). Sociocultural Aspects of Translating and Interpreting. Amsterdam: John Benjamins, 2006.

RASSOOL, N. Postmodernity, cultural pluralism and the Nation-state: problems of language rights, human rights, identity and power. Language Sciences. v. 20, N. 1, 1998, pp. 89-99.

RODRIGUES, C. H. Da interpretação comunitária à interpretação de conferencia: desafios para a formação de intérpretes de línguas de sinais. In: Congresso Nacional de Pesquisas em Tradução e Interpretação de Líbras e Língua Portuguesa, Santa Catarina, Anais, Florianópilis: UFSC, 2010.

RUDVIN, M. Power behind discourse and power in discourse in community interpreting: the effect of institutional power asymmetry on interpreter strategies. Revista Canaria de Estudios Ingleses. v. 51, nov/2005, p. 159179.

UNHCR. Global Trends. Forced Displacement in 2018. Switzerland, 2019. Disponível em: < https: //www.unhcr.org/globaltrends2018/>. Acesso em: 13 set 2019.

Valero-Garcés, C.; Martin, A. Crossing Borders in Community Interpreting: definitions and dilemmas. Amsterdam: John Benjamins, 2008.

VARGAS-URPI, M. State of the art in Community Interpreting research: Mapping the main research topics. Babel, v. 58, n. 1, 2012, p. 50-.

VOGT, W. P. Dictionary of statistics \& methodology: A nontechnical guide for the social sciences. Thousand Oaks, London, New Delhi: Sage, 1999. 
WADENSJÖ, C. Dialogue Interpreting and the Distribution of Responsibility. Hermes, Journal of Linguistics. v. 14, n. 8, 1995, p. 111-129.

Recebido em: 06/07/2020

Aceito em: $21 / 10 / 2020$

Publicado em dezembro de 2020 